\title{
DETEKSI DETAK JANTUNG BERBASIS WEB
}

\author{
Novita Karolina, Dedy Ristanto Hulu, Yonata Laia \\ Fakultas Teknlogi dan Ilmu Komputer, Universitas Prima Indonesia, Indonesia \\ Jl. Sekip simp.Sikambing \\ E-mail : dedyristanto6@gmail.com
}

\begin{abstract}
ABSTRAK- Denyut jantung merupakan indikasi penting dalam bidang kesehatan. Tujuan dari penelitian ini adalah agar mempermudah tenaga medis dalam melakukan perhitungan detak jantung secara digital dimanapun dan kapanpun. Tahapan penggunaan alat ini dimulai pada pulse sensor yang berfungsi untuk mendeteksi detak jantung manusia dapat diletakkan pada jari, dimana selanjutnya data yang diterima akan diproses dan diolah melalui Arduino dan hasil detak jantung akan dikirim dalam bentuk gelombang melalui modul ESP8266. Data yang dihasilkan yaitu Beat Per Minute (BPM), hasil rata-rata yang di dapat dalam bentuk grafik dan angka serta dapat menampilkan waktu selama pemakaian berlangsung dan alat membaca detak jantung dan akan di tampilkain ke web yang dapat diakses kapan saja.
\end{abstract}

Kata kunci : Deteksi detak jantung berbasis web

\section{PENDAHULUAN}

Jantung merupakan organ terpenting dalam tubuh manusia dan juga merupakan organ utama yang mensirkulasikan darah ke seluruh tubuh. Jantung memompakan darah ke seluruh tubuh sesuai dengan jumlah yang dibutuhkan oleh tubuh. Udara yang dihirup oleh paru-paru, dihantarkan darah menuju jantung, kemudian jantung dipompa keseluruh tubuh, terutama pada otot yang bekerja. Makin banyak otot yang bekerja, makin banyak kebutuhan oksigen, makin besar kekerapan denyut jantung kita perlukan. Semakin besar metabolisme dalam suatu organ, maka makin besar aliran darahnya. Hal ini menyebabkan kompensasi jantung dengan mempercepat detaknya dan memperbesar banyaknya aliran darah yang dipompakan dari jantung ke seluruh tubuh [1-3].

Sedangkan kerja jantung dapat dilihat dari detak jantung yang merupakan rambatan dari detak jantung, detak tersebut dihitung tiap menitnya dengan hitungan repetisi (kali/menit) atau dengan detak jantung maksimal dikurangi umur.

Perhitungan detak jantung dalam bidang kedokteran saat ini masih menggunakan cara manual, yaitu dengan cara pengukuran menggunakan Stethoscope atau dengan mengukur detak jantung pada pergelangan tangan dengan bantuan jam tangan [4, 5]. Karena secara umum pengukuran detak jantung masih dilakukan secara manual dan tidak semua orang dapat mengukur detak jant nn9 5ung mereka sendiri. Alat ini dirancang dengan menggunakan Arduino sebagai mikrokontroler dan sensor pulse sebagai alat pendeteksi detak jantungnya dan menggunakan aplikasi berbasis Website untuk menampilkan data detak jantung. Sistem koneksi antara alat dan aplikasi berbasis Website dengan menggunakan modul ESP 8266.

\section{METODE}

Perancangan perangkat pada sistem monitoring detak jantung ini meliputi perancangan perangkat keras dan perangkat protokol komunikasi. Berikut tedapat diagram alir penelitian, dimana perancangan rangkaian meliputi penentuan sensor detak jantung, perhitungan jumlah titik pengukuran, pembuatan skema monitoring, dan perancangan perangkat yang akan digunakan. Saat sistem diaktifkan, sensor akan mendeteksi jaringan atau organ yang bergerak seperti jantung[6-10]. Sensor akan mendeteksi sinyal tersebut dan kembali mengirimkannya ke mikrokontroler dalam bentuk data untuk diolah. Data yang dikirimkan berupa data analog yang kemudian diolah oleh ADC untuk diubah menjadi data digital. Sistem mikrokontroler akan menghitung jumlah data yang masuk dari sensor tersebut yang berupa data digital dalam jangka waktu yang telah ditentukan. Saat mikrokontroler mendeteksi adanya detak jantung, secara bersamaan juga data tersebut dikirim dan ditampilkan di web menggunakan aplikasi yang sudah dirancang sebelumnya[11-13]. Hasil akhir dari perhitungan jumlah detak jantung manusia tersebut akan ditampilkan ke web yang menunjukkan banyaknya detak jantung per detik.

Perancangan perangkat lunak dilakukan dengan membuat diagram alir terlebih dahulu dari perangkat lunak yang akan direalisasikan. Berikut adalah diagram alir (flowchart) dari program yang akan dibuat[14-16]. Pada bagian flowchart akan dijelaskan bahwa saat sistem diaktifkan, mikrokontroler akan melakukan inisialisasi port dan variable yang digunakan, yaitu port A sebagai port input dan port B sebagai output. Lalu variabel yang digunakan adalah variabel D sebagai jumlah pulsa atau detak, dan variabel $\mathrm{T}$ sebagai variabel 
pengambilan data pulse Pada kondisi normal, kedua variabel ini bernilai 0. Alur kerja dari sistem ini akan bekerja saat tombol start diaktifkan. Pada saat tombol start diaktifkan maka sensor mulai dihasilkan pengelohan sinyal arduino uno dan pengiriman sinyal melalui ESP 8266 yang akan ditampilkan melalui Web. Berikut gambar flowchart:

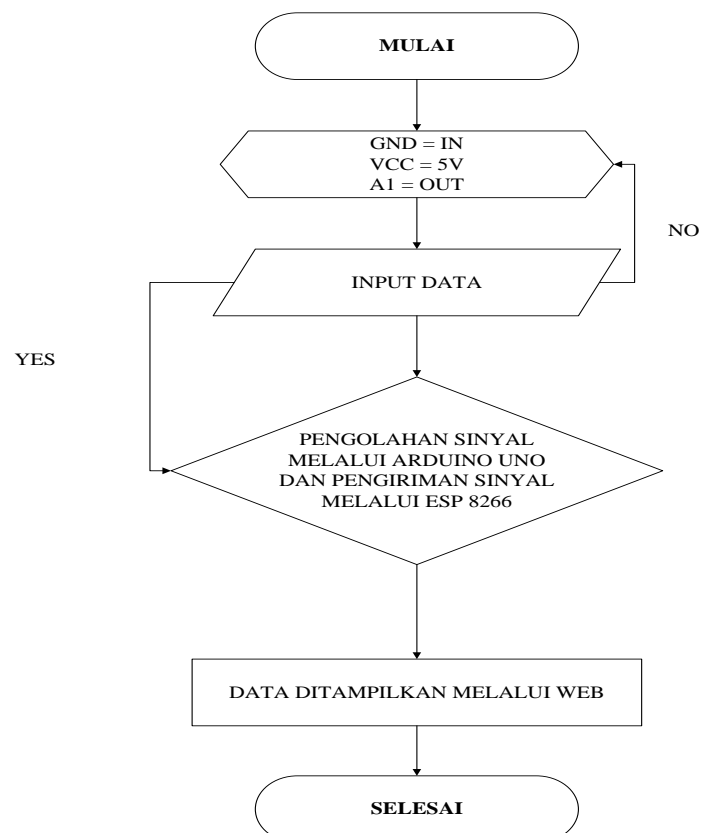

Gambar 1. Diagram Alir Sensor Detak Jantung.

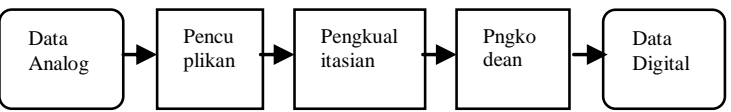

Gambar 2. Proses Konversi Analog ke Digital.

Analog to Digital Converter adalah suatu perangkat yang mengubah suatu data kontinu terhadap waktu (analog) menjadi suatu data diskrit terhadap waktu (digital). Pin analog pada Arduino (dan mikrokontroler lain pada umumnya) dapat digunakan untuk input dan output digital. Hanya saja pin analog memiliki fitur untuk dapat mengubah sinyal analog yang masuk menjadi nilai digital yang mudah diukur. Pin digital hanya dapat mengenali sinyal 0 volt sebagai nilai LOW dan 5 volt sebagai nilai HIGH. Sedangkan Pin analog dapat mengenali sinyal pada rentang nilai voltase tersebut. Hal ini sangat berguna ketika kita hendak mengukur sesuatu dari sensor dan menggunakan nilai masukan tersebut untuk keperluan lain.

\section{Hasil Dan Pembahasan}

Pada proses pengujian alat pendeteksi detak jantung ini peneliti menggunakan aplikasi penghitung detak jantung berbasis web merupakan sebuah aplikasi mendeteksi dan menghitung detak jantung seseorang. Berikut ini adalah implementasi memonitoring detak jantung berbasis web:

Tabel 1. Implementasi Penghitung Detak Jantung.

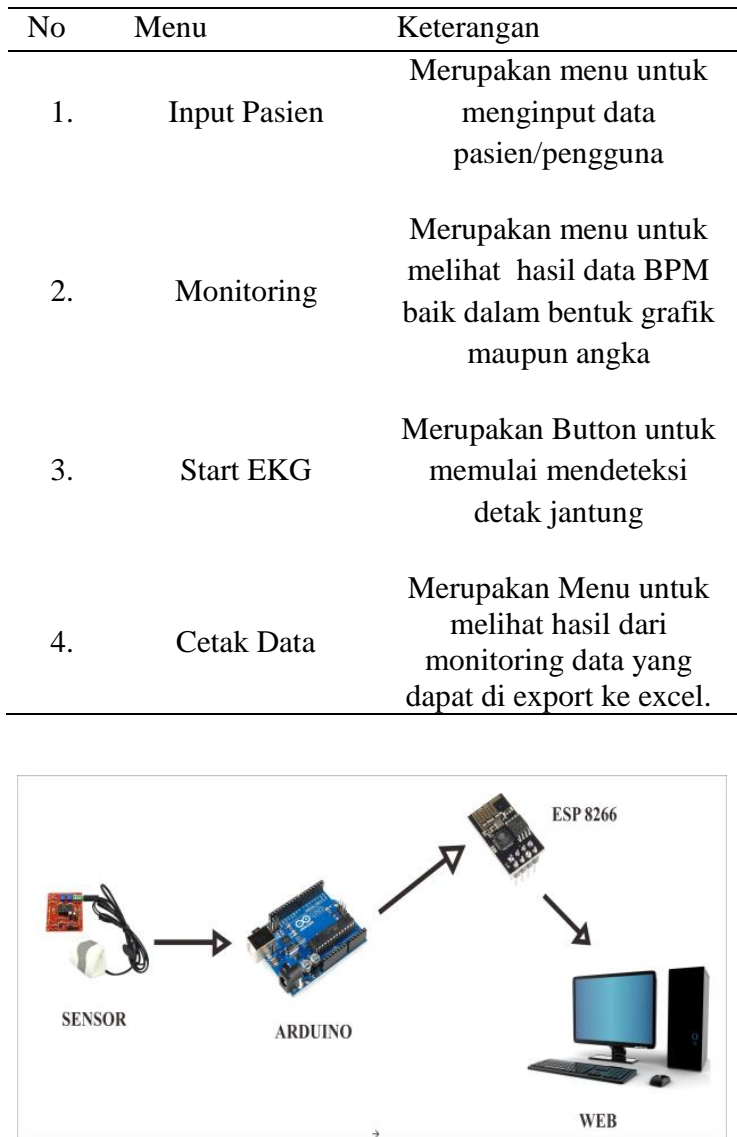

Gambar 3. Gambar Perancangan Alur Sinyal Sistem.

Alat ini dirancang untuk memantau detak jantung secara realtime dan kontinyu dengan menggunakan sensor pulse sebagai sensor pembaca detak jantung. Data dari sensor pulse diproses oleh Arduino lalu data itu akan dikirim ke Web melalui ESP 8266. Setelah proses pengolahan data berjalan dengan baik maka data detak jantung akan tampil secara realtime dalam bentuk grafik.

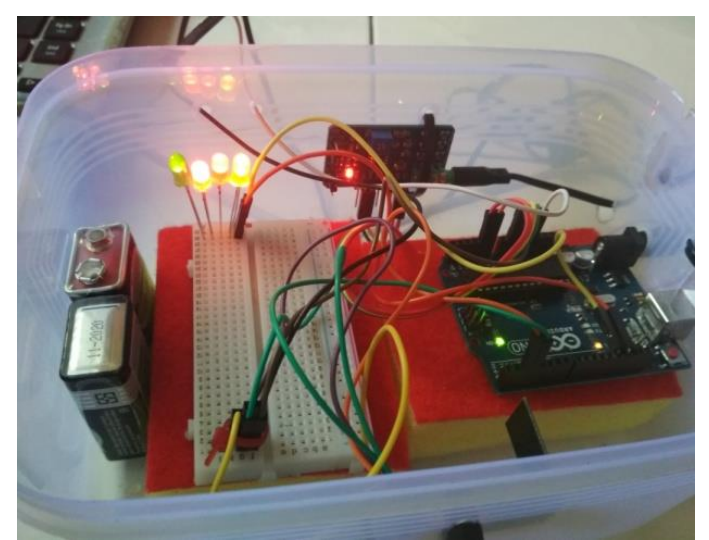

Gambar 4. Rancangan Model Alat. 
Pada rangkaian alat monitoring detak jantung ini menggunakan 4 buah komponen utama yang terdiri dari mikrokontroler Arduino Uno, ESP8266, sensor easy pulse Heart, dan papan breadbroard yang mana akan dihubungkan dengan masing-masing pin yang ada pada perangkat.

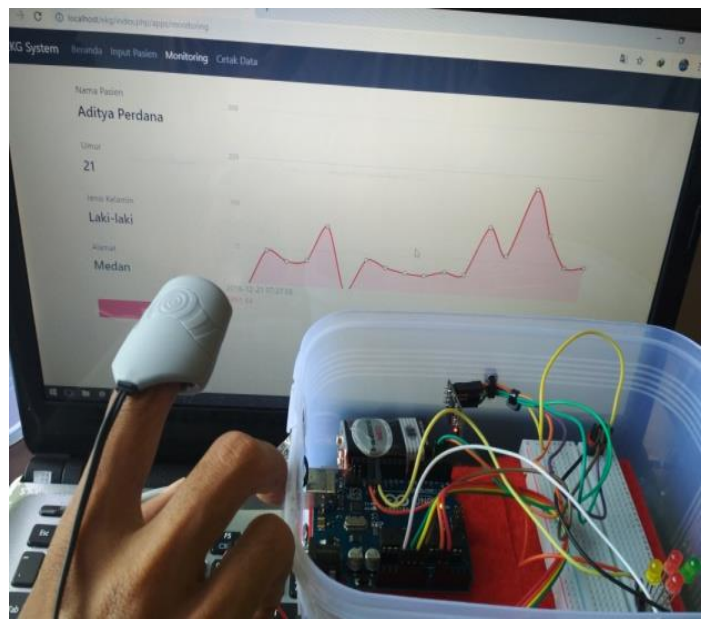

Gambar 5. Implementasi Alat
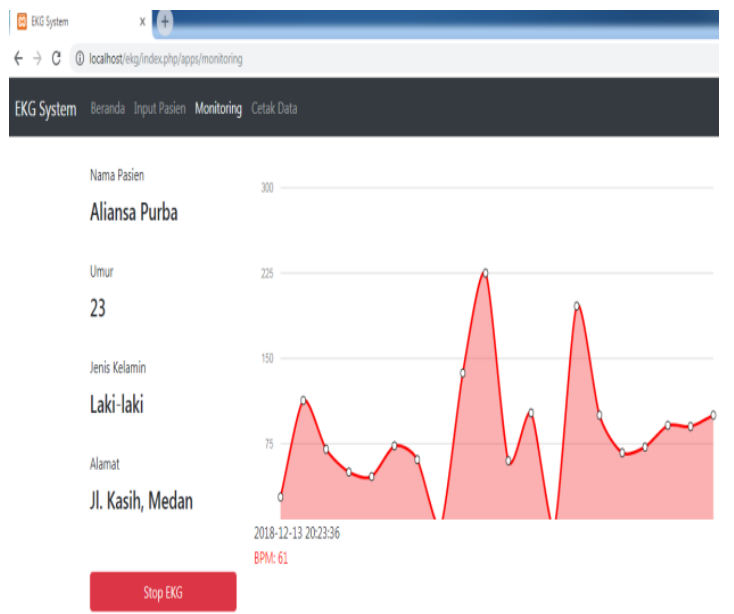

Gambar 6. Tampilan Hasil Pada Monitoring Sensor Detak Jantung

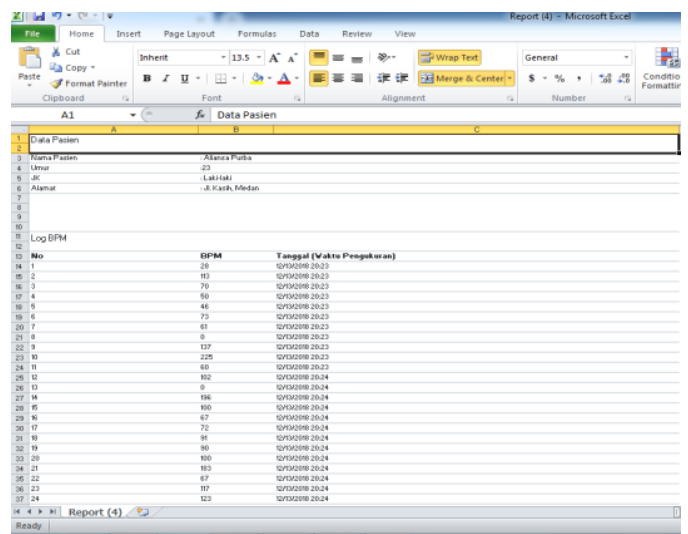

Gambar 7. Tampilan Hasil Output ke Excel.

\section{Kesimpulan}

Berdasarkan hasil analisa statistik yang dilakukan pada sistem ini, subjek eksperimen menerima hasil rata-rata yang di dapat dalam bentuk grafik dan angka serta dapat menampilkan waktu selama pemakaian berlangsung. Alat Monitoring Detak Jantung berbasis Web ini memiliki respon input sensor yang berubah-ubah sesuai dengan kondisi detak jantung yang terbaca oleh sensor pulse. Rancangan alat yang digunakan terdiri dari rangkaian sensor, rangkaian amplifier untuk detak jantung, rangkaian ESP 8266 dan mikrokontroler. Noise yang terdapat pada sinyal diabaikan, karena hanya mencari detakan jantung, sehingga dapat diketahui nilai pulse heartrate nya dan datanya dapat di ekspor ke dalam format tertentu dimana datanya bisa diolah ulang oleh pihak medis. Rangkaian pendeteksi detak jantung ini menghitung jumlah pulse atau detak selama 30 detik dengan jumlah hasil perhitungan detak selama 30 detik dikalikan dengan 2 sehingga mendapatkan hasil perhitungan detak selama 1 menit.

\section{PENUTUP}

Kesimpulan Data yang dihasilkan yaitu Beat Per Minute (BPM), hasil rata-rata yang di dapat dalam bentuk grafik dan angka serta dapat menampilkan waktu selama pemakaian berlangsung dan alat membaca detak jantung kemudian akan di tampilkan ke web yang dapat diakses kapan saja.

Sarannya adalah untuk penelitian lebih lebih lanjut agar dilakukan pengembangan yang sebelumnya monitoring berbasis web dikembangkan menjadi monitoring berbasis android.

\section{DAFTAR PUSTAKA}

[1] Muhammad, N.; Nur, A.; Syahrir; Fadlan, D.; Musyawira F. H." Deteksi Denyut Jantung dengan Metode Sensor Pulse Berbasis Ardiuno" Makassar. 6. 2015.

[2] Sandi. "Heart Definition." Surabaya. 10. 2016.

[3] Kasenda. Marunduh and Wungouw. “Blood Pressure Wave”. Solo.10. 2014.

[4] Herru and Priatna. "Pulse of Blood Flow", Jakarta. 10-11. 2015.

[5] Hermawan, Subiyono and Rahayu. "Heart Work". 4. 2012.

[6] Fachrul Rozie, Ferry Hadary, F.Trias Pontia W. "Designing a Based Pulse / Heart Rate Monitoring Tool Web"; 3-4. 2018.

[7] Barsheshet A, Hod H, Oieru D, Goldenberg I, Sandach A, Beigel R, et al. "Right precordial lead (V4R) ST-segment elevation is associated with worse 
prognosis in patients with acute anterior myocardial infarction". J Am Coll Cardiol;58(5):548-9. 2011.

[8] R, Perez. "Design of medical electronic devices". San Diego: Academic Press. (2002).

[9] L.Floyd, Thomas. "Electronic Device Conventional Current Version". New Jersey: Pearson Education. (2008).

[10] Ludeman, C. "Fundamentals of Digital Signal Processin”. New York State University. 1987.

[11] Papaloukas, C., Fotiadis, D.I., Likas, A., Michalis, L.K. An Ischemia. "Detection Method Based on Arti-ficial Neural Networks". 2001.

[12] Mitra, S.K. "Digital Signal Processing A Computer-Based Approach". McGrawHill Series. Singapore. 1998.

[13] Kini S, Leroy Weaver. "Normal and Variant Coronary Arterial and Venous Anatomy on High-Resolution CT Angiography”. AJR Am J Roentgenol;188(6):1665-74. 2007.

[14] J. Muthuswamy. "Standard Handbook of Biomedical Engineering and Design, Chapter 18 Biomedical Signal Analysis, Tempe, Arizona": McGrawHill. 2003.

[15] Huang, H.K. "PACS and Imaging Informatics Basic Principles An Applications. Hoboken": John Wiley \& Sons, Inc. 2004.

[16] Brodal, Per. "The Central Nervous System: Structure and Function”. Oxford University Press. 2004.

[17] S. Salivahanan, A. Vallavaraj, Gnanapriya. "Digital Signal Processing". McGraw-Hill. Singapore. 2001.

[18] Dittrich, K.I. and Walls, R.M. Hyperkalemia: "ECG manifesttations and considerations. The Journal of Emergency Medicine”. 4, 449-55. doi:10.1016/0736-4679(86)90174-5. (1986)

[19] Tompskin, W. J, "Biomedical Signal Processing”. Prentice Hall. New Jersey. (1993).

[20] Webster, J.G, John Wiley \& Son,Inc. "Bioinstrumentation". Singapore. (2004).

[21] Chen, C.Y.; Chang, C.L.; Chang, C.W.; Lai, S.C.T.; Chien, F.; Huang, H.Y.; Chiou, J.C.; Luo, C.H. Sensors "A Low-Power Bio-Potential Acquisition System with Flexible PDMS Dry Electrodes for Portable Ubiquitous Healthcare Applications". 13, 30773091. 2013.
[22] Andreoni, G.; Fanelli, A.; Witkowska, I.; Perego, P.; Fusca, M.; Mazzola, M.; Signorini, M.G. "Sensor Validation for Wearable Monitoring System in Ambulatory Monitoring: Application to Textile Electrodes". In Proceedings of the 7th International Conference on Pervasive Computing Technologies for Healthcare, Venice, Italy, 5-8 May 2013; pp. 169-175.

[23] Morón, M. J.; Luque, R.; Casilari, E. Sensors, "On the capability of smartphones to perform as communication gateways in medical wireless personal area networks". 14(1), 575-594. 2014.

[24] Song, W.; Yu, H.; Liang, C.; Wang, Q.; Shi, Y.; "Body monitoring system design based on web smartphone". In Proceedings of 2012 World Congress on Information and Communication Technologies WICT 2012. Trivandrum, India. ; pp. 11471151. 30 October -2 November 2012

[25] Ren, Y.; Pazzi, R. W. N.; Boukerche, A. "Monitoring patients via a secure and mobile healthcare system". Wireless Communications. IEEE. 17(1), 59-65. 2010.

[26] W. Patterson. "Artificial Neural Ntework Theory and Applications". Jhon Wiley and Sons, Inc. 1995.

[27] Raju, M. "Heart-Rate and ECG Monitor Using The MSP430FG439". Application Report. s, A. (2005). "ECG Based Cardiac Abnormality Detection Using Crosswavelet Transform. International Jurnal of Advance Science and Technology". (2015).

[28] Huang, H.K. "PACS and Imaging Informatics Basic Principles And Applications. Hoboken": John Wiley \& Sons, Inc. 2004. 